\title{
Molecular analysis of a Clostridium butyricum NCIMB 7423 gene encoding 4- $\alpha$-glucanotransferase and characterization of the recombinant enzyme produced in Escherichia coli
}

\author{
Sayed K. Goda, ${ }^{1}$ Omima Eissa, ${ }^{2}$ Muhammad Akhtar ${ }^{2}$ \\ and Nigel P. Minton'
}

Author for correspondence: Nigel P. Minton. Tel: +44 1980 612562. Fax: +44 1980611310. e-mail : nigel.minton@camr.org.uk

1 Department of Molecular Microbiology, Centre for Applied Microbiology and Research, Porton Down, Salisbury SP4 OJG, UK

2 Department of Biochemistry, University of Southampton, Bassett Crescent East. Southampton S016 7PX, UK

\begin{abstract}
An Escherichia coli clone was detected in a Clostridium butyricum NCIMB 7423 plasmid library capable of degrading soluble amylose. Deletion subcloning of its recombinant plasmid indicated that the gene(s) responsible for amylose degradation was localized on a $1.8 \mathrm{~kb}$ NspHI-Scal fragment. This region was sequenced in its entirety and shown to encompass a large ORF capable of encoding a protein with a calculated molecular mass of $57184 \mathrm{Da}$. Although the deduced amino acid sequence showed only weak similarity with known amylases, significant sequence identity was apparent with the 4- $\alpha$-glucanotransferase enzymes of Streptococcus pneumoniae (46.9\%), potato $(42.9 \%)$ and $E$. coli (16.2\%). The clostridial gene (designated ma/Q) was followed by a second ORF which, through its homology to the equivalent enzymes of E. coli and S. pneumoniae, was deduced to encode maltodextrin phosphorylase (MalP). The translation stop codon of malQ overlapped the translation start codon of the putative malP gene, suggesting that the two genes may be both transcriptionally and translationally coupled. $4-\alpha$-Glucanotransferase catalyses a disproportionation reaction in which single or multiple glucose units from oligosaccharides are transferred to the 4-hydroxyl group of acceptor sugars. Characterization of the recombinant $C$. butyricum enzyme demonstrated that glucose, maltose and maltotriose could act as acceptor, whereas of the three only maltotriose could act as donor. The enzyme therefore shares properties with the $E$. coli MalQ protein, but differs significantly from the glucanotransferase of Thermotoga maritima, which is unable to use maltotriose as donor or glucose as acceptor. Physiologically, the concerted action of 4- $\alpha$-glucanotransferase and maltodextrin phosphorylase provides $C$. butyricum with a mechanism of utilizing amylose/maltodextrins with little drain on cellular ATP reserves.
\end{abstract}

Keywords: MalQ, 4- $\alpha$-glucanotransferase, Clostridium butyricum, starch degradation

\section{INTRODUCTION}

There is currently great interest in using biological fermentation as a possible alternative to fossil-fuelbased industries for the production of bulk chemical feedstocks and high-added-value chemicals. This is

The EMBL accession number for the amino acid sequence determined in this work is $L 37874$. especially true of the genus Clostridium, members of which exhibit a diverse fermentative repertoire (Minton \& Clarke, 1989). Clostridium acetobutylicum and its ability to produce the solvents acetone and butanol has attracted particular interest. Intensive research with this clostridial species has resulted in the development of gene transfer methodologies (Minton et al., 1993) and in the cloning of many of the genes encoding key enzymes of primary metabolism (Papoutsakis \& Bennett, 1993). 
Economic processes, such as the C. acetobutylicumbased acetone-butanol-ethanol (ABE) fermentation, will of necessity use low-cost, carbohydrate-based substrates such as amylose. The enzymes involved in amylose degradation in clostridia have, however, received comparably little attention. This is despite the fact that amylase activity in C. acetobutylicum may be a limiting factor in solvent production (Lin \& Blaschek, 1983; Hermann et al., 1985). Such a bottleneck could be circumvented by amplifying the endogenous levels of enzymes involved in amylose metabolism, or by endowing the organism with heterologous enzymes through gene cloning technology. With the latter strategy in mind, we constructed a gene library in Escherichia coli of the genome of an amylolytic strain of Clostridium butyricum, and screened for clones capable of degrading amylose. In the present communication we describe the characterization of one such clone, shown to produce a 4- $\alpha$-glucosyltransferase analogous to the MalQ protein of the E. coli maltose regulon (Schwartz, 1987).

\section{METHODS}

Bacterial strains, plasmids and growth conditions. The source of chromosomal DNA was C. butyricum NCIMB 7423. The $E$. coli strains used as hosts for plasmid and M13 recombinants were strains TG1 $[\mathrm{K}-12, \Delta($ lac-proAB) supE thi hsdD5/F' traD36 proAB lacl $\left.{ }^{\mathrm{Z}} \mathrm{ZMM} 15\right]$ and $E$. coli CGSC\#6153 $\mathrm{F}^{-}$ araD139 $\Delta($ argF-lac $) 205$ flbB5301 ptsF25 rpsL malQ63 bglR15 deocl], respectively. Cloning vectors used were plasmids pMTL20/21 (Chambers et al., 1988) and pMTL32 (Whelan et al., 1992), and phages M13mp18 and M13mp19 (YanischPerron et al., 1985). C. butyricum was cultivated in a semisynthetic medium, essentially as described by Barker et al. (1959). E. coli was routinely cultivated in L broth $(1 \%$ tryptone, $0.5 \%$ yeast extract, $0.5 \% \mathrm{NaCl}$ ). E. coli CGSC\#6153 was cultivated in M9 minimal medium (Sambrook et al., 1989). Solidified medium consisted of $L$ broth or M9 minimal media with the addition of $2 \%(w / v)$ agar (Bacto-Difco). The antibiotic used for the maintenance and the selection of transformants was $50 \mu \mathrm{g}$ ampicillin $\mathrm{ml}^{-1}$. Recombinant transformants were detected by their colourless appearance on $\mathrm{L}$ agar plates containing $100 \mu \mathrm{g}$ IPTG $\mathrm{ml}^{-1}$ and $50 \mu \mathrm{g} \mathrm{X-Gal}$ $\mathrm{ml}^{-1}$.

DNA manipulations. Transformation of $E$. coli and large-scale plasmid isolation procedures were as previously described (Minton et al., 1983). Small-scale plasmid isolation was by the method of Holmes \& Quigley (1981), whilst chromosomal DNA from C. butyricum was prepared essentially as described by Marmur (1961). Restriction endonucleases and DNA modifying enzymes were purchased from Northumbria Biologicals and were used under the conditions recommended by the supplier. Digests were electrophoresed in $1 \%(\mathrm{w} / \mathrm{v})$ agarose slab gels on a standard horizontal system (Bio-Rad Model LH4), employing Tris/borate/EDTA (0.09 M Tris/ borate, $0.002 \mathrm{M}$ EDTA) buffer. The isolation of DNA restriction fragments from agarose gels using electroelution and DNA-DNA hybridizations were undertaken as described by Sambrook et al. (1989). Hybridizations were undertaken at $65^{\circ} \mathrm{C}$, followed by two $15 \mathrm{~min}$ washing periods in $6 \times \mathrm{SSC}$ containing $0 \cdot 1 \%(\mathrm{w} / \mathrm{v}) \mathrm{SDS}$ at $55^{\circ} \mathrm{C}$. M13 template DNA was sequenced by the dideoxynucleotide method of Sanger $e t$ al. (1980) using a modified version of T7 polymerase, Sequenase (Tabor \& Richardson, 1987). Analysis of generated nucleotide sequence data was undertaken using DNASTAR (Computer Genetics Group, Madison, WI, USA).

Identification and processing of recombinant clones. Recombinant clones capable of bringing about the breakdown of amylose were detected by screening for colourless halos around recombinant colonies on $\mathrm{L}$ agar supplemented with $1 \%(\mathrm{w} / \mathrm{v})$ amylose following flooding with iodine solution $(1 \%, w / v$, iodine/potassium iodide). Colonies were lysed prior to staining by exposure to chloroform vapour. E. coli clones found to be producing an activity capable of degrading amylose were cultivated in $200 \mathrm{ml}$ Luria broth supplemented with $50 \mu \mathrm{g}$ ampicillin $\mathrm{ml}^{-1}$ at $37^{\circ} \mathrm{C}$ to an OD of 10 at $600 \mathrm{~nm}$. Cells were harvested by centrifugation, washed in $20 \mathrm{ml} 1 \times$ TE buffer (10 mM Tris/ $\mathrm{HCl}, 0 \cdot 1 \mathrm{mM}$ EDTA, pH 7.0) and resuspended in $20 \mathrm{mM}$ Tris $/ \mathrm{HCl}, \mathrm{pH} 7 \cdot 5$. Cell disruption was achieved by sonication ( $20 \mathrm{kcycles} \mathrm{s}^{-1}, 2 \mathrm{~A}$ ) for five $30 \mathrm{~s}$ intervals on ice. Cellular debris was removed by centrifugation at $17000 \mathrm{~g}$ for $40 \mathrm{~min}$ and the amylose-degrading activity precipitated with $45-55 \%$ saturated $\left(\mathrm{NH}_{4}\right)_{2} \mathrm{SO}_{4}$ and dialysed against water for $2 \mathrm{~d}$ prior to assay. Protein concentration was measured by the method of Bradford (1976), using BSA as the standard.

Enzyme assay. Glucanotransferase activity was quantified by measuring the reduction of amylose. The assay mixture contained $0.1 \%(\mathrm{w} / \mathrm{v}$ ) maltose, $20 \mathrm{mM}$ Tris $/ \mathrm{HCl}, \mathrm{pH} 7.5$ and enzyme in a final volume of $3 \mathrm{ml}$. Following incubation at $37^{\circ} \mathrm{C}, 0.1 \mathrm{ml}$ samples were withdrawn at various time intervals, mixed with $1 \mathrm{ml} 0.02 \%$ iodine/potassium iodide solution, and the decrease in absorbance at $620 \mathrm{~nm}$ measured. One unit of the enzyme activity was arbitrarily defined as the amount of enzyme which causes a change in absorbance of 1.0 in $15 \mathrm{~min}$ under the above conditions.

TLC chromatographic analysis. In certain instances the reaction products liberated were further characterized with respect to molecular size by thin-layer ascending chromatography on $0.2 \mathrm{~mm}$ silica-gel-coated aluminium sheets (type 60; Merck) employing a solvent system of $1 \mathrm{M}$ lactic acid /acetone/2-propanol (2:4:4, by vol.). Carbohydrate spots were visualized by spraying the chromatogram with aniline/ diphenylamine reagent (Sigma) and incubated at $160^{\circ} \mathrm{C}$ for $10 \mathrm{~min}$. In certain experiments use was made of $\left[\mathrm{U}-{ }^{14} \mathrm{C}\right] \mathrm{mal}-$ tose and $\left[\mathrm{U}-{ }^{14} \mathrm{C}\right]$ glucose (Amersham). The radioactive products were visualized by autoradiography.

\section{RESULTS}

\section{Isolation of recombinants able to degrade amylose}

A gene library was constructed by inserting into the Bam HI site of pMTL21 sized (4-7 kb) DNA fragments from C. butyricum NCIMB 7423 chromosomal DNA partially digested with Sau3A. Over 6000 putative recombinant clones were obtained and screened for the presence of amylose-degrading activity, using an in situ plate test. A total of four clones were identified which produced an enzyme activity capable of breaking down amylose within the vicinity of a lysed colony. Plasmid DNA was isolated from all four clones and subjected to digestion with a number of different restriction enzymes. This analysis indicated that no one clone contained a common DNA insert. The clone which appeared to be producing the most activity, as judged by halo size, was therefore selected for further analysis and its recombinant plasmid designated pSKG10. That this clone was 


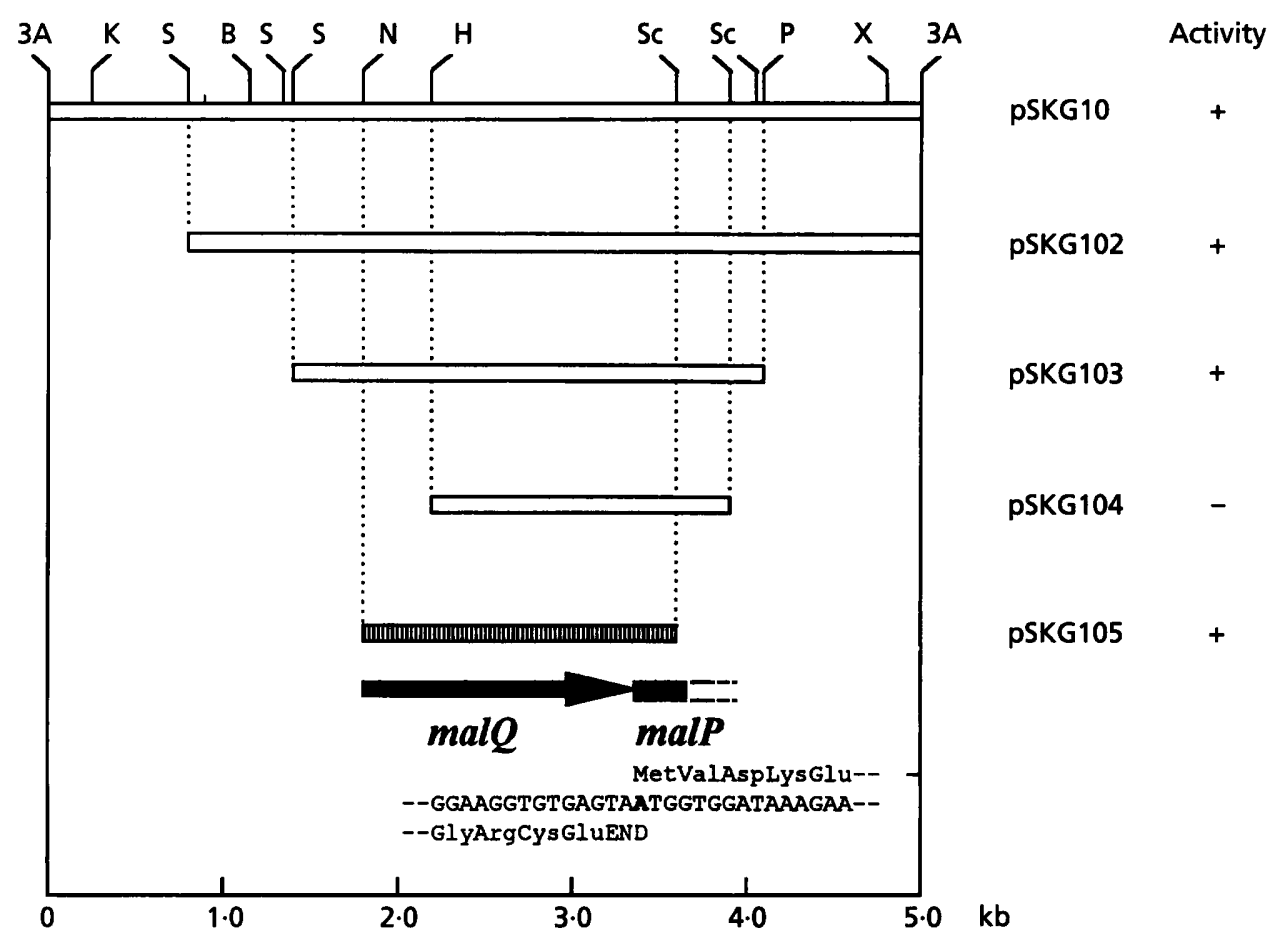

Fig. 1. Physical maps of plasmids containing malQ. All the indicated $C$. butyricum-derived chromosomal fragments were cloned into appropriate sites within the PMTL21 polylinker region. Where an appropriate site was not available, the fragments were blunted by treatment with T4 DNA polymerase and inserted into the Smal site. The ability of cells carrying each plasmid to bring about amylose degradation is indicated by a ' +'. Plasmid pSKG104 had lost this ability.

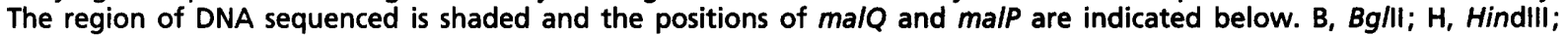
K, Kpnl; N, Ndel; P, Pvull; S, Styl; Sc, Scal; X, Xmnl; 3A, Sau3A. The partial nucleotide sequence of the extreme 3'-end of the malQ gene and the extreme 5 '-end of the malP gene is also presented. The ' $A$ ' nucleotide shared by the stop and start codons of malQ and malP, respectively, is shown in bold.

indeed capable of degrading amylose was confirmed by incubating crude cell lysates with amylose and measuring the observed change in intensity $\left(\Delta A_{620}\right)$ of iodinestaining. This indicated that cells of $E$. coli TG1[pSKG10] grown for $16 \mathrm{~h}$ produced up to $20 \mathrm{U}$ per mg total protein of amylose degrading activity per litre of culture.

\section{Characterization of the cloned gene}

Plasmid pSKG10 DNA was purified and shown to confer on a plasmid-free $E$. coli host the ability to degrade amylose when introduced by transformation. To confirm the clostridial origin of the cloned DNA, pSKG10 was radioactively labelled and used as a probe against chromosomal DNA isolated from C. butyricum NCIMB 7423 which had been digested with various restriction enzymes. In each case, pSKG10-derived DNA was shown to hybridize to discrete clostridial DNA fragments and not to control fragments derived from the E. coli chromosome (data not shown).

Having established the authenticity of pSKG10, a more detailed restriction map of its insert was derived (Fig. 1) and its size assessed as being $5.0 \mathrm{~kb}$ in length. To establish the position of the gene(s) responsible for amylose breakdown, a number of deletion sub-clones were made by excising subfragments from within the pSKG10 insert and re-cloning them into sites within the polylinker region of pMTL21. The ability of the resultant plasmids to elicit amylose degradation in $E$. coli was then tested using the in situ plate test. The regions sub-cloned are shown in Fig. 1. These experiments indicated that the smallest fragment which could be sub-cloned and still retain gene(s) responsible for amylose degradation was a $1.8 \mathrm{~kb}$ NspHI-Scal fragment (pSKG105, Fig. 1). Sub-cloning of a DNA fragment from which a further $425 \mathrm{bp}$ had been removed from the $N s p H I$ end of this region resulted in a plasmid, pSKG104, which no longer conferred the ability to degrade amylose on $E$. coli. It was concluded that the gene(s) responsible resided between the $\mathrm{NspHI}$ and $S c a \mathrm{I}$ sites.

\section{Nucleotide sequence determination}

To sequence the insert of pSKG105, some 50 templates carrying random $500 \mathrm{bp}$ fragments were derived by the sonication procedure (Minton et al., 1986). Prior to sonication, the isolated $1.8 \mathrm{~kb} \mathrm{NspHI}$ (blunt-ended)Scal fragment was circularized by self-ligation. The region analysed proved to be $1849 \mathrm{bp}$ in length and to display an $\mathrm{A}+\mathrm{T}$ content of $70 \mathrm{~mol} \%$, consistent with its 
C.BUT

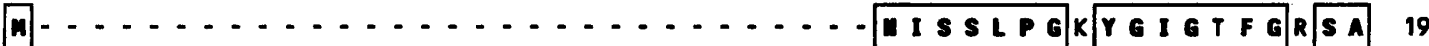

S.PNE

POTATO

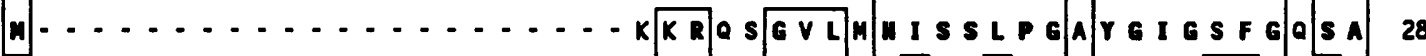
AVPAVGEDFPIDYADHLPKRDPNDRRRAGILLUPT SFPGPYGIGDLGPQA 50

C.BUT

YEFCDFLEKAGQKYUAILPLG TSY- - - GDSPYOSFSAFA MPYFIDLD 65

S.PME

POTAT

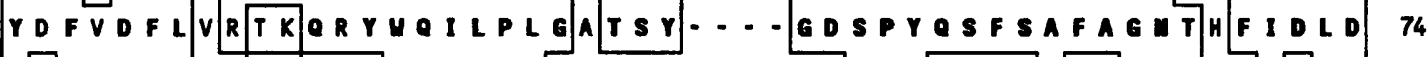
FKELDULH LAGCSLLAVLPLVPPGKRGNEDGSPYSGODAN CG TLLLSLE 100

C.BUT

S.PNE

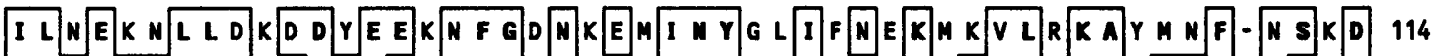
I LVEOGLLE A S L E G V D F G S D A S E V D Y A K I Y Y A R R P L L E K A V K R F F E V G D 124

POTAT

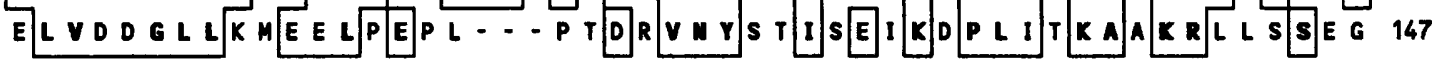

C.BUT

S.PNE

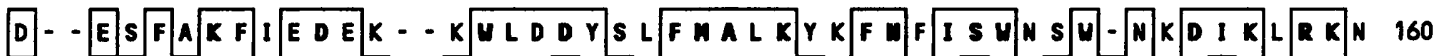
POTATO

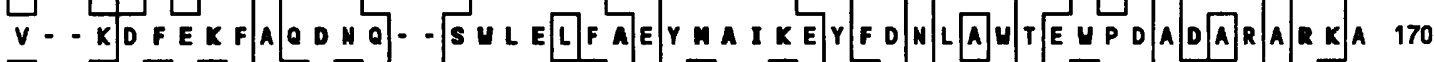

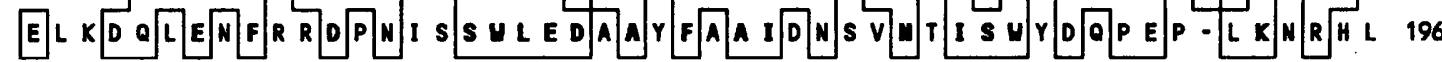

C. BUT

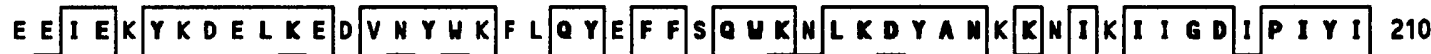
S.PNE

POTATO

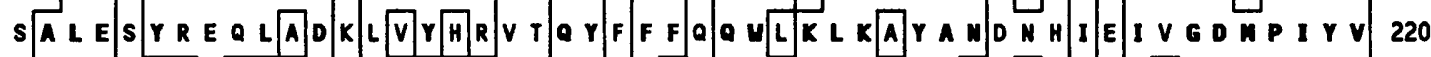

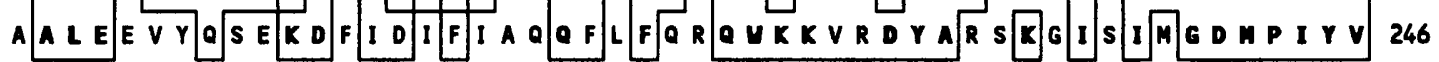

C.BUT

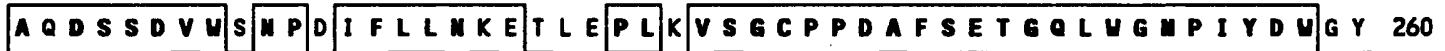

S.PNE

POTATO

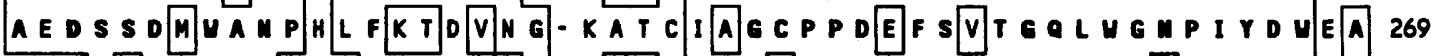
GYHSADVUANKKQFLLNRKGF-PLIVSGVPPDAFSETGQLUGSPLYDUKA 295

C.BUT

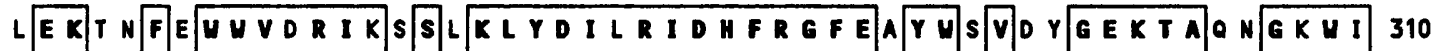
S.PNE

POTATO

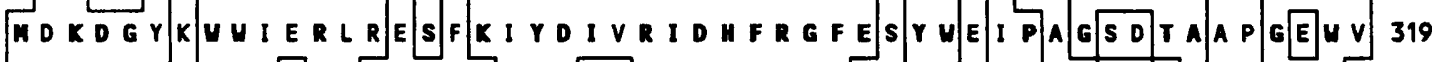

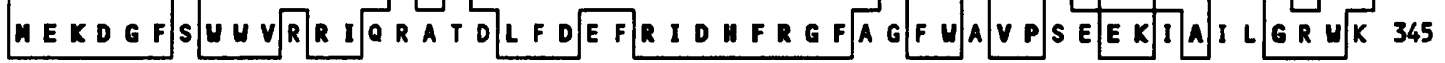

C.BUT

KGPEMKLFN IKERTIGDIEIIAEDLGYLTEETLEFRKRTGFPGNKIIAFA 360

S.PNE

POTATO KG PGYKLFA|A VKEELLEL II I E DLGFMTDEVIELRERTGFPENKILAFA 369

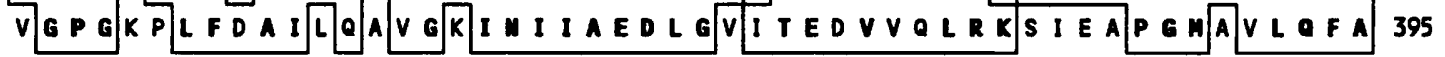

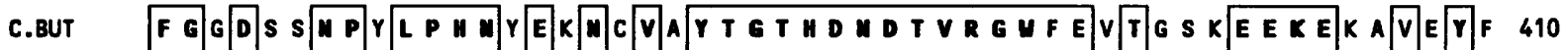

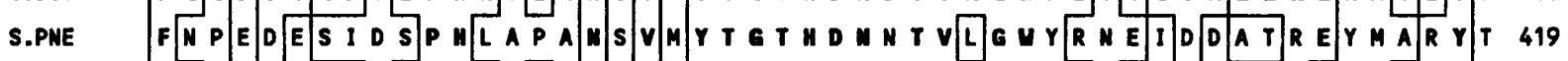

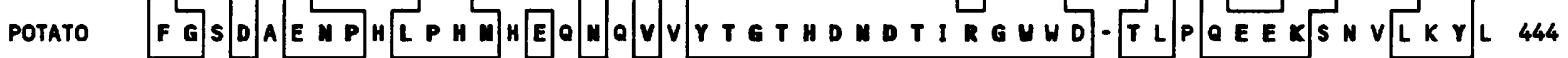

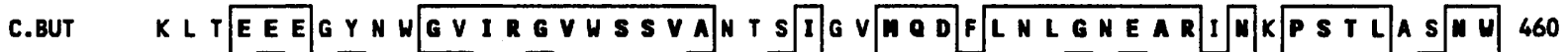

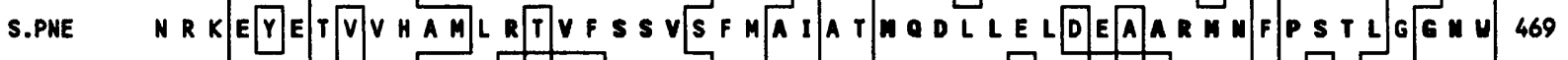

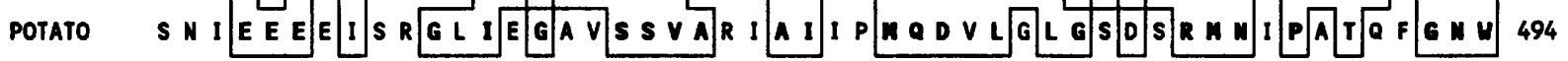

C.BUT

S.PNE

POTATO

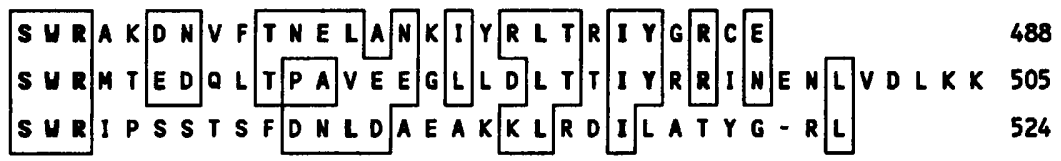

Fig. 2. Amino acid similarity between the 4- $\alpha$-glucanotransferases of $C$. butyricum, $S$. pneumoniae and potato. Both identical and chemically similar amino acids are boxed. Identical amino acids are emboldened. C.BUT, MalQ of C. butyricum; S.PNE, MalM of S. pneumoniae; POTATO, 4- $\alpha$-glucanotransferase of potato. 
derivation from C. butyricum (Cummins \& Johnson, 1973). Translation of the sequence revealed the presence of a single major ORF, initiating at position 118 with an AUG start codon and terminating at position 1581 with a UAA stop codon. The encoded polypeptide was therefore composed of some 487 amino acids and had a predicted molecular mass of $57184 \mathrm{Da}$.

Comparative alignment of the deduced amino acid sequence of the polypeptide encoded by the identified ORF with characterized amylase or glucoamylase sequences indicated only a low level of similarity. Significant homology ( $46.9 \%$ identity) was, however, apparent (Fig. 2) with the published sequence of the MalM protein of Streptococcus pneumoniae (Lacks et al., $1982)$ and $(42.9 \%$ identity) with $\alpha$-glucanotransferase of potato (Takaha et al., 1993). These proteins correspond to 4- $\alpha$-glucanotransferase, or formerly amylomaltase (Palmer et al., 1976). In contrast, little homology (16.2\% identity) was evident between the clostridial protein and the extensively characterized $4-\alpha$-glucanotransferase of E. coli (Pugsley \& Dubreuil, 1988). A similar lack of similarity between the $S$. pneumoniae MalM protein and $\alpha$-glucanotransferase of potato (Takaha et al., 1993) with the E. coli MalQ enzyme has been previously noted (Pugsley \& Dubreuil, 1988). Despite this low level of similarity, the enzymic properties of the clostridial protein (see below) are identical to those reported for the $E$. coli malQ gene product. In view of this functional identity, the clostridial enzyme was designated MalQ, and its encoding gene malQ.

The enzyme 4- $\alpha$-glucanotransferase (EC 2.4.1.25) is involved in maltose and maltodextrin metabolism. In both $E$. coli and $S$. pneumoniae these enzymes act in concert with a phosphorylase (EC 2.4.1.1), the encoding gene of which is located within the immediate vicinity of both malQ and malM. An examination of the nucleotide sequence of the NspHI-ScaI fragment revealed the large ORF was followed after its stop codon by a incomplete ORF, which apparently terminated at a site external to the sequenced region. The translated amino acid sequence, comprising 89 amino acid residues, was aligned with the maltodextrin phosphorylases of $E$. coli and S. pneumoniae. Significant homology was found. In particular, a 30 amino acid segment of the translated polypeptide (residues 58-87) exhibited 53\% and $63 \%$ identity to the equivalent regions of MalP from $E$. coli and S. pneumoniae, respectively. In the light of these similarities the incomplete gene was designated malP, and its encoded protein MalP.

\section{Characterization of the recombinant enzyme}

The ability of $E$. coli-derived recombinant cell-free extracts to bring about the release of glucose from amylose had been demonstrated when the gene was initially isolated through the use of a glucose oxidase assay (data not shown). However, other enzymes besides glucotransferases liberate glucose from amylose, most notably glucoamylase or $\alpha$-amylase. To definitely establish that the C. butyricum malQ gene did indeed

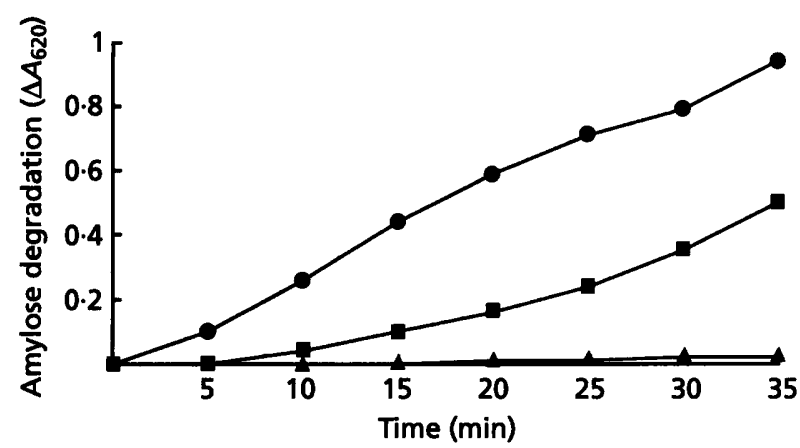

Fig. 3. Enhancement of amylose degradation in $C$. butyricum by maltose. A mixture containing $0.1 \mathrm{ml}$ cell-free extract (prepared as described in Methods from E. coli CGCS\#6153 cells containing pSKG105) and $100 \mu \mathrm{g}$ soluble amylose was incubated at $37^{\circ} \mathrm{C}$ in $1 \mathrm{ml} 20 \mathrm{mM}$ Tris/ $/ \mathrm{HCl}, \mathrm{pH} 7.5$ with and without $100 \mu \mathrm{g}$ maltose. At various time intervals, $0.1 \mathrm{ml}$ aliquots of reaction mixture were mixed with $1 \mathrm{ml} 0.02 \%$ iodine/potassium iodide solution and the absorption measured at $620 \mathrm{~nm}$. The indicated data points are from reactions in which extracts prepared from cells containing plasmid pSKG105 were incubated with amylose alone (D), or with amylose and maltose (O). Control experiments, in which a cell-free extract derived from host cells carrying only the cloning vector (pMTL21) was incubated with amylose and maltose, gave a barely detectable activity $(\boldsymbol{\Lambda})$.

encode a glucanotransferase, a further series of experiments were undertaken.

In the first instance, plasmid pSKG105 was shown to complement the malQ mutation of the $E$. coli strain CGSC\#6153 by plating transformed cells on M9 minimal agar containing maltose as sole carbon source. Transformant colonies were not obtained in control experiments in which the plasmid utilized was the cloning vector pMTL21. Using CGSC\#6153 transformed with pSKG105, further evidence that the clostridial MalQ protein is a glucanotransferase was obtained when it was demonstrated that the size of the zone of amylose degradation around a lysed recombinant colony was significantly increased by the presence of maltose $(1 \%)$ in the agar medium (data not shown). This stimulatory effect could be measured more directly by monitoring the change in iodine-staining properties during the conversion of amylose, or a mixture of amylose and maltose, over a period of time. The data obtained (Fig. 3) demonstrated that the presence of maltose in the reaction mixture abolished the considerable lag in amylose breakdown observed when cell extracts were incubated in the presence of amylose alone. This lag in amylose degradation may be attributable to the initial absence of a suitable acceptor, such as maltose, for amylose-derived glucanosyl units. A delay in enzyme activity in the absence of maltose would not occur if the clostridial enzyme was an amylase.

Glucanotransferase catalyses a disproportionation reaction in which single or multiple glucose units from oligosaccharides are transferred to the 4-hydroxyl group of acceptor sugars. It follows that in the presence of a glucanotransferase and amylose, radioactive label ini- 


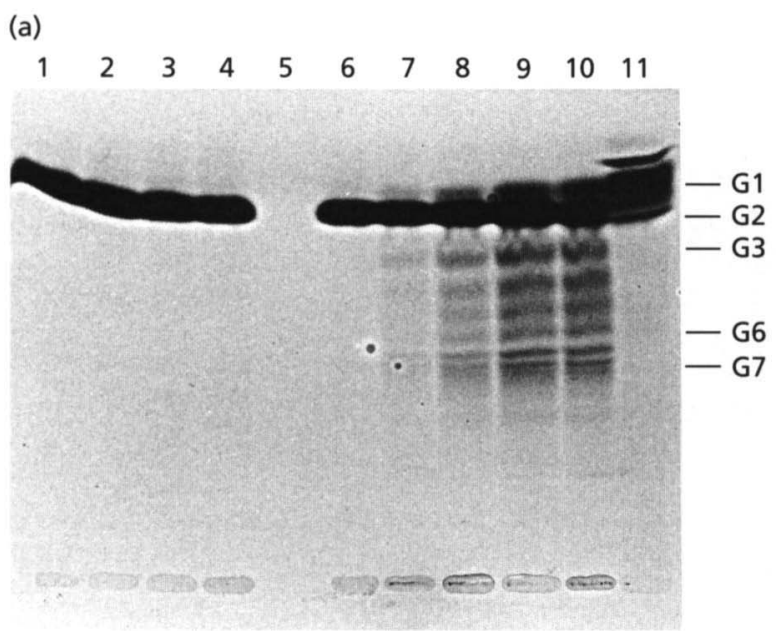

(b)
Fig. 4. TLC of radioactive products formed from $\left[{ }^{14} \mathrm{C}\right]$ maltose in the presence of amylose (a) or maltotriose (b). Reactions were performed at $37^{\circ} \mathrm{C}$ in $1 \mathrm{ml} 20 \mathrm{mM}$ Tris/ $\mathrm{HCl}, \mathrm{pH} 7.5$ and contained $0.01 \mathrm{ml}$ of a cell-free extract derived from $E$. coli CGSC\#6153 cells containing PSKG105, $100 \mu \mathrm{g}$ soluble amylose (a) or $100 \mu \mathrm{g}$ maltotriose (b), and $1 \mu \mathrm{Ci}(37 \mathrm{kBq})\left[{ }^{14} \mathrm{C}\right]$ maltose. At various time intervals, $100 \mu \mathrm{l}$ samples were withdrawn, and subjected to TLC. In (a), the samples in lanes 6-11 were withdrawn after $0,5,10,15,20 \mathrm{~min}$ and $24 \mathrm{~h}$, respectively. Lanes 1-4 represent the corresponding control experiment (samples withdrawn after $0,5,10$ and $20 \mathrm{~min}$, respectively, where extracts were derived from cells carrying the cloning vector alone). In (b), the reaction was carried out as described in (a) but maltotriose was used in place of amylose. The samples in lanes 9-15 were withdrawn after $0,5,10,15,20,25$ and 30 min, respectively. Lanes 1-7 represent the corresponding control. The positions of the molecular mass standards used in the assay are marked on the right of each chromatogram: G1, glucose; G2, maltose; G3, maltotriose; G6, maltohexaose; and G7, maltohepaose.

tially present in an acceptor sugar molecule should be seen to become distributed amongst a range of maltodextrin species. This is precisely what was observed. Thus, for example, when an extract from the recombinant clone was incubated with $\left[{ }^{14} \mathrm{C}\right]$ maltose and amylose, a series of labelled sugars were evident (Fig. 4a), one of the labelled species being maltotriose. This demonstrates that the clostridial enzyme can use maltose as an acceptor to which it is able to transfer a glucosyl (i.e. single glucose) unit to yield maltotriose. The formation of higher ${ }^{14} \mathrm{C}$-containing sugars emphasizes that the enzyme may also transfer glucanosyl units (oligomers of glucose). Essentially identical results were obtained when amylose was incubated with $\left[{ }^{14} \mathrm{C}\right]$ glucose (data not shown), demonstrating that this sugar could also act as an acceptor molecule. In all cases, whatever the acceptor, it was evident that after $24 \mathrm{~h}$ incubation, glucose and maltose were the sole final reaction products (Fig. 4a). This underlines the fact that, as is the case with the E. coli MalQ enzyme, glucose and maltose act only as acceptors and not donors of glucose units. As shown by Palmer et al. (1976), the production of glucose from maltose by such enzymes depends on the presence of catalytic amounts of higher oligodextrins. These act as glycosyl donors, which are continuously recycled upon transfer of the glycosyl moiety to a maltose acceptor

Further light on the substrate specificity of the enzyme was shed by the profile of products obtained from the incubation with $\left[\mathrm{U}-{ }^{14} \mathrm{C}\right]$ maltose and unlabelled maltotriose. The formation of labelled maltotriose in such experiments (Fig. 4b) once again emphasized that a glucosyl unit from maltotriose may be transferred to maltose. This observation, together with the labelling of higher sugars, demonstrated that maltotriose can act as a donor sugar.

\section{DISCUSSION}

In the present study we have used an in situ plate test to identify a clostridial gene, mal $Q$, encoding $4-\alpha$-glucanotransferase. In common with the equivalent genes of $E$. coli and S. pneumoniae, the gene encoding a maltodextrin phosphorylase is located in the immediate vicinity of the 4- $\alpha$-glucanotransferase gene. In E. coli, the two genes form an operon, in which the malP gene precedes malQ. In both C. butyricum NCIMB 7423 and $S$. pneumoniae the order is reversed. Whether the two $C$. butyricum genes are co-transcribed was not established. However, their extremely close proximity suggests that this is extremely likely. Furthermore, as the stop codon of the clostridial malQ overlaps the start codon of malP (Fig. 1), there is a strong possibility that the two genes are translationally coupled. The evolution of active measures to ensure the co-ordinate production of the two encoded enzymes is consistent with their important complementary roles in maltodextrin metabolism.

On the smallest DNA fragment subcloned, the $1.8 \mathrm{~kb}$ NspHI-ScaI fragment, the malQ gene is preceded by only $117 \mathrm{bp}$. The identity of sequences within this region important in the expression of malQP was not determined. A sequence typical of clostridial ribosomebinding sites (Young et al., 1989) is present immediately $5^{\prime}$ to the malQ start codon, but the identification of sequences important in transcription will require further experimental analysis. Direct evidence that transcription signals are present was obtained when this fragment was 
inserted into the polylinker region of plasmid pMTL32 to give pSKG132. Cells carrying pSKG132 were shown to produce equivalent levels of amylose-degrading activity to the same $E$. coli cells carrying plasmid pSKG105. Thus, as the cloning sites of pMTL32 are flanked by transcriptional terminators, transcription of malQ in pSKG132 must initiate from an endogenous promoter. As these experiments were undertaken in $E$. coli, it remains to be seen whether this same region has promoter activity in C. butyricum.

The identity of the clostridial MalQ protein as a glucanotransferase, rather than an amylase or glucoamylase, was indicated by the demonstration that single or multiple glucose units were transferred from oligosaccharides to the acceptor sugars, glucose, maltose or maltotriose. The occurrence of multiple disproportionation reactions during in vitro incubation meant that it was not possible to determine the size of the largest glucanosyl units which can be transferred. However, the formation of products of ten glucose units in incubations performed with amylose and maltose (Fig. 4b) could indicate that at least eight glucanosyl units may be transferred by the clostridial enzyme. Following an extended period of incubation (lane 15, Fig. 4b), radioactivity was solely distributed amongst maltose and glucose. Whilst the generation of oligodextrins from maltose shows that the C. butyricum MalQ is a glucanotransferase, the degradation of amylose, as measured by reduced binding of iodine, suggests that some hydrolytic activity may provide low-molecularmass acceptors. Alternatively, low-molecular-mass glycosyl acceptors may be generated by MalQ.

Our studies also established that both glucose and maltose, in addition to maltotriose, could act as acceptor molecules. The action of the enzyme on maltotriose in the presence of excess $\left[{ }^{14} \mathrm{C}\right]$ glucose and the formation of radioactive maltotriose (data not shown) indicates that maltotriose could also act as a donor. In this respect the properties of the clostridial 4-glucanotransferase are similar to those for the corresponding enzyme (MalQ) from E. coli (Pugsley \& Dubreuil, 1988) and $\alpha$-glucanotransferase of potato (Takaha et al., 1993). They differ from those of the enzyme (GTase) isolated from Thermotoga maritima (Liebl et al., 1992) which uses neither maltotriose as the donor sugar nor glucose as the acceptor sugar.

Physiologically, the concerted action of $\alpha$-glucanotransferase and maltodextrin phosphorylase provides the cell with a mechanism of utilizing maltodextrins with little drain on cellular ATP. Assuming that the MalP enzyme exhibits similar catalytic properties to the equivalent $E$. coli protein, the co-operative action of the clostridial MalQ and MalP enzymes may be illustrated by a hypothetical example involving maltotriose. After three rounds of disproportionation, 4-glucanotransferase may produce maltodextrin containing up to nine glucose units (i.e. maltononaose) and release three equivalents of glucose. For the further metabolism of glucose, ATP is required. However, maltononaose will enter the hexose phosphate pool, by the action of maltodextrin phosphorylase, until maltopentaose is produced which, as maltodextrin phosphorylase is inactive against oligosaccharides of less than six sugar units in length, is no longer a substrate for the enzyme. Maltopentaose, through the action of 4-glucanotransferase, may undergo further rounds of disproportionation producing higher maltodextrins for use by maltodextrin phosphorylase. In addition to their catabolic role, the two enzymes may also be involved in the storage process by transferring the maltodextrin skeleton to acceptors producing higher polymers. The role of $4-\alpha$-glucanotransferase in the biosynthesis of long 1,4-glucan (amylose) is shown by the properties of $E$. coli mutants devoid of maltodextrin phosphorylase (Schwartz, 1987). These mutants, when grown in the presence of maltodextrin, accumulate large amounts of amylose, formed through a succession of disproportionation events catalysed by the transferase.

\section{Concluding remarks}

In the present study we have isolated a gene from clostridia which encodes a product capable of degrading starch. On the basis of the following observations, the encoded enzyme was concluded to encode an $\alpha-4$ glucanotransferase: the enzyme catalysed the synthesis of higher molecular mass oligosaccharides; activity was stimulated by the presence of maltose; the gene was able to complement an E. coli malQ mutant; and the deduced amino acid sequence exhibited significant identity with characterized $\alpha$-4-glucanotransferase enzymes, including those of $S$. pneumoniae $(46.9 \%)$, and potato $(42 \cdot 9 \%)$.

\section{ACKNOWLEDGEMENTS}

The authors wish to thank Nicola Minion for typing this manuscript. N.P.M wishes to acknowledge the financial support of the BBSRC, research grant T04089.

\section{REFERENCES}

Barker, H. A., Smyth, R. D., Wilson, R. M. \& Weissbach, H. (1959). The purification and properties of $\beta$-methylaspartase. $J$ Biol Chem 234, 320-328.

Bradford, M. M. (1976). A rapid and sensitive method for the quantitation of microgram quantities of protein utilizing the principle of protein-dye binding. Anal Biochem 72, 248-254.

Chambers, S. P., Prior, S. E., Barstow, D. A. \& Minton, N. P. (1988). The pMTLnic-cloning vectors. I. Improved polylinker regions to facilitate the use of sonicated DNA for nucleotide sequencing. Gene 68, 139-149.

Cummins, C. S. \& Johnson, J. L. (1973). Taxonomy of the clostridia : wall composition and DNA homologies in Clostridium butyricum and other butyric acid-producing clostridia. J Gen Microbiol 67, 33-46.

Hermann, M., Fayolle, F., Marchal, R., Podvin, L., Sebald, M. \& Vandecasteele, J. P. (1985). Isolation and characterisation of butanol resistant mutants of Clostridium acetobutylicum. Appl Environ Microbiol 50, 1238-1243.

Holmes, D. S. \& Quigley, M. (1981). A rapid boiling method for the preparation of bacterial plasmids. Anal Biochem 114, 193-197. 
Lacks, S. A., Dunn, J. J. \& Greenberg, B. (1982). Identification of base mismatches recognised by the heteroduplex-DNA-repair system of Streptococcus pneumoniae. Cell 31, 327-336.

Liebl, W., Feil, R., Gabelsberger, J., Kellermann, J. \& Schleifer, K.-H. (1992). Purification and characterisation of a novel thermostable 4- $\alpha$-glucanotransferase of Thermotoga maritima cloned in Escherichia coli. Eur J Biochem 207, 81-88.

Lin, Y. L. \& Blaschek, H.P. (1983). Butanol production by a butanol-tolerant strain of Clostridium acetobutylicum in extruded corn broth. Appl Environ Microbiol 45, 966-973.

Marmur, J. (1961). A procedure for the isolation of deoxyribonucleic acid from microorganisms. $J$ Mol Biol 3, 208-218.

Minton, N. P. \& Clarke, D. J. (1989). Biotechnology Handbook, vol. 3, Clostridia. New York: Plenum.

Minton, N. P., Atkinson, T. \& Sherwood, R. F. (1983). Molecular cloning of the Pseudomonas carboxypeptidase $\mathrm{G}_{2}$ gene and its expression in Escherichia coli and Pseudomonas putida. J Bacteriol 156, 1222-1227.

Minton, N. P., Bullman, H. M. S., Atkinson, T., Scawen, M. D. \& Gilbert, H. J. (1986). Nucleotide sequence of the Erwinia chrysanthemi 1066 L-asparaginase gene. Gene 46, 25-35.

Minton, N. P., Brehm, J. K., Swinfield, T. J., Whelan, S. M., Rodger, M. L., Bodsworth, N. \& Oultram, J. D. (1993). Clostridial cloning vectors. In The Clostridia and Biotechnology, pp. 119-150. Edited by D. T. Woods. New York: Butterworths.

Palmer, T. N., Ryman, B. E. \& Whelan, W. J. (1976). The action pattern of amylomaltase from Escherichia coli. Eur J Biochem 69, 105-115.

Papoutsakis, E. T. \& Bennett, G. N. (1993). Cloning, structure, and expression of acid and solvent pathway genes of Clostridium acetobutylicum. In The Clostridia and Biotechnology, pp. 157199. Edited by D. T. Woods. New York: Butterworths.
Pugsley, A. P. \& Dubreuil, C. (1988). Molecular characterisation of malQ, the structural gene for the Escherichia coli enzyme amylomaltase. Mol Microbiol 2, 473-479.

Sambrook, J., Fritsch, E. F. \& Maniatis, T. (1989). Molecular Cloning: a Laboratory Manual. Cold Spring Harbor, NY: Cold Spring Harbor Laboratory.

Sanger, F., Coulson, A. R., Barrell, B. G., Smith, A. J. H. \& Roe, B. A. (1980). Cloning in single-stranded bacteriophage as an aid to rapid DNA sequencing. $J$ Mol Biol 143, 161-178.

Schwartz, M. (1987). The maltose regulon. In Escherichia coli and Salmonella typhimurium: Cellular and Molecular Biology, pp. 1482-1502. Edited by F. C. Neidhardt, J. L. Ingraham, K. Brooks Low, B. Magasanik, M. Schaechter \& H. E. Umbarger. Washington, DC: American Society for Microbiology.

Tabor, S. \& Richardson, C. C. (1987). DNA sequence analysis with modified T7 DNA polymerase. Proc Natl Acad Sci USA 84, 4767-4771.

Takaha, T., Yanase, M., Okada, S. \& Smith, S. M. (1993). Disproportionating enzyme of potato (4- $\alpha$-glucanotransferase, EC 2.4.1.25). Eur J Biochem 268, 1391-1396.

Whelan, S. M., Elmore, M. J., Bodsworth, N. J., Brehm, J. K., Atkinson, T. \& Minton, N. P. (1992). Molecular cloning of the Clostridium botulinum structural gene encoding the type B neurotoxin and determination of its entire nucleotide sequence. Appl Environ Microbiol 58, 2345-2354.

Yanisch-Perron, C., Vieira, J. \& Messing, J. (1985). Improved M13 phage cloning vectors and host strains: nucleotide sequences of M13mp18 and pUC19 vectors. Gene 33, 103-119.

Young, M., Minton, N. P. \& Staudenbauer, W. L. (1989). Recent advances in clostridial genetics. FEMS Microbiol Rev 63, 1-25.

Received 20 March 1997; revised 5 June 1997; accepted 10 June 1997. 